\title{
Utility and Efficiency of «The Gentle Injection of Fibrin Glue» in Neurosurgical Operative Field: Technical Note
}

\author{
Sabrina Hallout ${ }^{1 *}$, Li Cai ${ }^{1,2}$, Emad Aboud ${ }^{1}$ and Ali F Krisht ${ }^{1}$ \\ ${ }^{1}$ Arkansas Neuroscience Institute, CHI St. Vincent Infirmary, Little Rock, Arkansas, \\ USA \\ ${ }^{2}$ Department of Neurosurgery, The First Affiliated Hospital of University of South \\ China, Hengyang, China
}

\section{Mini Review \\ Volume 3 Issue 2}

Received Date: October 21, 2019

Published Date: November 12, 2019

*Corresponding author: Sabrina Hallout, Arkansas Neuroscience Institute, CHI St. Vincent Infirmary, Little Rock, Arkansas, USA, Email: sabrina.hallout@neurochirurgie.fr

\section{Abstract}

The first publication reporting the used fibrin sealant during intracranial tumor surgery for difficult hemostatic problems was in 1984. The neurosurgical operative field requires rigorous hemostasis, inopportune use of bipolar coagulation can be dangerous and lead to a post-operative ischemic complication. Otherwise, coagulation is sometimes not feasible because of the noble anatomical juxtaposed with the hemorrhagic focus. There is still a great deal of confusion concerning optimal use of bio surgical hemostatic agent, because of the wide range of products, performing their hemostatic action in different ways. Using Tisseel VH fibrin sealant glue as a biological adhesive glue indicated as an adjuvant local hemostatic in neurosurgical operative field was inspired by limitations related to other surgical techniques. We will expose in this technical note our team's experience of using a Tisseel glue. The goal of this technical note is to deliver to young neurosurgeon or to inexperimented team some tips and recommendations about fibrin glue and its efficiency in reducing neurosurgical morbidity. We report the utilisation of Tisseel in many cases of neurosurgery when conventional method failed. An additional literature search was performed in the PubMed, Embase, and Cochrane databases to compare our tips to published one. The film glue is deposited as a "wrap" "around a suture, it can be used as an adjuvant for dissection intracranial parenchyma, it can be most efficient than surgical wax for some bone bleeding around emissary veins.

Keywords: Fibrin glue; Glue film; Bleeding; Hemostatic agent; Neurosurgical field

\section{Introduction}

The first case report about tisseel was published in 1984. Tisseel is described as « fibrin sealant (containing a combination of fibrinogen, Factor XIII, fibronectin, and albumin and thrombin, together with $\mathrm{CaC12}$ ). The components are mixed, and the thrombin transforms the fibrinogen into a fibrin monomer, the aggregated fibrin 


\section{International Journal of Surgery \& Surgical Techniques}

strands of which are further cross- linked by activated Factor VIII in the presence of $\mathrm{Ca}++$ ions. The resulting fibrin clot is improved in mechanical stability following alpha-chain cross-linking with Factor XIII A. Tisseel was used in a patient to control continuous bleeding from a highly malignant glioma after all common hemostatic procedures had failed. The fibrin sealant controlled the bleeding within 5 minutes and the postoperative course was uneventful. Microscopy at autopsy 3 months later suggested a nonreactive organization of fibrin on the tumor surface [1]. The neurosurgical operative field requires rigorous haemostasis for a good visibility of the anatomical structures and for prevention of hemorrhagic suffusion. Inopportune use of bipolar coagulation can be dangerous and lead to a post-operative ischemic complication. Otherwise, coagulation is sometimes not feasible because of the noble anatomical juxtaposed with the hemorrhagic focus. Hemostasis of the neurosurgical field is performed by using a mechanical effect: applying a direct pressure with cotonoid or realizing ligation or clipping when it is feasible. The second option is thermal effect by bipolar electrocoagulation using tissue resistance. When these techniques are non-efficient, the neurosurgeon should use some adjuvants named surgical hemostatic agents. Their main properties are adhesion of two biological tissue layers in vivo by mechanical effect of the glue film, and local hemostasis [2-4]. Fibrin glue is a biological adhesive consisting in a solution of concentrated human fibrinogen which is activated by the addition of bovine thrombin and calcium chloride. Under the effect of thrombin, fibrinogen is converted into fibrin monomer. The translucide glue film observed on the field as a sticky material is surnamed " fibrinoma » exerting a haemostatic action [5-7]. We will expose in this technical note our team's experience of using a Tisseel glue. The goal of this technical note is to deliver to young neurosurgeon or to inexperimented team some tips and recommendations about fibrin glue and its efficiency in reducing neurosurgical morbidity. We report the utilisation of Tisseel in many cases of neurosurgery when conventional method failed.

\section{Materials and Methods}

We performed a systematic review of the literature according to PRISMA guidelines using multiple electronic databases. Medical literature on «tisseel » was identified by searching databases (including MEDLINE, EMBASE and in-house AdisBase), Additional information was also requested from the company developing the drug. We focused our research on association « tisseel+neurosurgical procedure+hemostasis» with exclusion criteria as « CSF leakage » and « spinal surgery ». We focused on review published in last 10 years about humans. We tried to compare our findings based on our personal use in neurosurgical field to the usefulness of tisseel in published literature from 2009 to 2019. Additional information was also requested from the company developing the drug on their website (baxter Healthcare Corp., Deerfield, IL) We used Tisseel VH fibrin sealant as an adjuvant for hemostasis in adult's brain tumor surgery when control of bleeding by conventional surgical techniques (such as suture, ligature, and cautery) is ineffective or impossible. For Topical Use Only, we use it as a thin layer by dripping or spraying using cannula, the medium gentle volume injection is generally $4 \mathrm{~mL}$ and enough to entirely cover the intended application area. We used it with the Duploject system.

\section{Results}

We will expose in this technical note our team's experience of using a Tisseel glue. The goal of this technical note is to deliver to young neurosurgeon or to inexperimented team some tips and recommendations about fibrin glue and its efficiency in reducing neurosurgical morbidity. Biological adhesives have been used for several years in the repair of cerebrospinal fluid (CSF) leaks, sealing of the vascular anastomosis sites, reinforcements of aneurysmal clippings, and hemostasis after resection of brain tumors, in the sinusal surgical reconstruction and water tightness of the surgical cavity to prevent CSF leak. Procedures which seemed to be impossible or difficult by conventional neurosurgical techniques such as transcavernous surgical approach could be accomplished when a gentle injection of Fibrin glue is used for stopping venous bleeding into different cavernous sinus compartments $[7,8]$. It was used as an adjuvant to surgical techniques after suture or ligature for reinforcement, after dura mater repair for avoiding CSF from operative field [9]. The cerebro-spinal fluid leakage can be managed by a gentle injection of Fibrin glue after dura mater repair. In addition its property for water tightness of surgical cavity is specially appreciated in transsphenoidal approach [10-14]. We experimented bleeding from epidural venous plexus in spine surgery [15]. Veins connected to the superior petrosal sinus and tentorial sinus during microvascular decompression. We observed that the fibrin glue has a faster clotting time. Its local application allows the formation of a faster clot as a « fibrinoma » very efficient in venous bleeding. We used it for stopping bleeding for emissary veins or for bone bleeding after drilling and exposing sigmoid sinus [16,17]. We used it for its adhesive property in order to fix teflon 


\section{International Journal of Surgery \& Surgical Techniques}

between artery and nerve avoiding [18]. Fibrin sealant is rarely used alone and oftentimes allogeneic patches are used to reinforce the suture line and to close gaps [19]. Since many years ago, our team have already used this glue as adjuvant in brain parenchyma dissection for protecting adjacent tissue $[20,21]$. As benefit reported, when surgeon use fibrin glue for hemostasis, perioperative allogeneic blood transfusion rate decreased [22] the rate of periopertaive complications in posterior fossa decompression is reduced [23]. We have noticed during one case that Fibrin glue can be used for nerve repair, by either direct coaptation or tubulization. The glue film is an alternative to conventional suture repair, particularly in case of small-size-nerve reconstruction [24-28].

\section{When can we avoid to use it?}

In isolated cases, fibrin glue can produce severe anaphylaxis. Such reactions may especially be seen, if the preparation is applied repeatedly, or administered to patients known to be hypersensitive to aprotinin or any other constituents of the product. Tissel does not have to be injected directly inside a vessel, or into the circulatory system or into highly vascularized tissue. Intravascular application of Tisseel can lead to intravascular coagulation, can result in life-threatening thromboembolic events, and can increase acute allergic reactions The non-indication of the product are patients with a known hypersensitivity to aprotinin [29]. We don't observe any side effects which are described as rare but possible in the notice of Tisseal as hypersensitivity or allergic reactions (which may include angioedema, burning and stinging at the application site, bradycardia, bronchospasm, chills, dyspnoea, flushing, generalized urticaria, headache, hives, hypotension, lethargy, nausea, pruritus, restlessness, tachycardia, tightness of the chest, tingling, vomiting, wheezing) [29]. Nevertheless, no transmissible diseases have been reported.

\section{Conclusion}

According to our experience, when conventional techniques failed, bleeding is stopped by using fibrin glue avoiding to our patient when electrocoagulation is ineffective; when a vascular anastomosis must be sealed. The film glue is deposited as a "wrap" "around a suture, it can be used as an adjuvant for dissection intracranial parenchyma, it can be most efficient than surgical wax for some bone bleeding around emissary veins.
Acknowledgment: I want to think you the chairman professor Krisht for receiving me in his neurosurgical operative field.

\section{References}

1. Kennedy JG, Saunders RL (1984) Use of cryoprecipitate coagulum to control tumor-bed bleeding. Case report. J Neurosurg 60(5): 1099-1101.

2. Duarte AP, Coelho JF, Bordado JC, Cidade MT, Gil MH (2012) Surgical adhesives: Systematic review of the main types and development forecast. ProgPolym Sci 37(8): 1031-1050.

3. Spotnitz WD (2012) Hemostats, sealants, and adhesives: A practical guide for the surgeon. Am Surg 78(12): 1305-1321.

4. Jain R, Wairkar S (2019) recent developments and clinical applications of surgical glues: An overview. Int J Biol Macromol 137: 95-106.

5. Nistor RF, Chiari FM, Maier H, Hehl K (1997) The fixed combination of collagen with components of fibrin adhesive-a new hemostypic agent in skull base procedures. Skull Base Surg 7(1): 23-30.

6. Thompson DF, Letassy NA, Thompson GD (1988) Fibrin glue: a review of its preparation, efficacy, and adverse effects as a topical hemostat. Drug Intell Clin Pharm 22(12): 946-952.

7. Krayenbühl N, Hafez A, Hernesniemi JA, Krisht AF (2007) Taming the cavernous sinus: technique of hemostasis using fibrin glue Neurosurgery 61(3): E52.

8. Toyooka T, Otani N, Wada K, Tomiyama A, Ueno H, et al. (2017) Effect of Fibrin Glue Injection Into the Cavernous Sinus for Hemostasis During Transcavernous Surgery on the Cerebral Venous Draining System. Oper Neurosurg (Hagerstown) 13(2): 224-231.

9. Green AL, Arnaud A, Batiller J, Eljamel S, Gauld J, et al. (2014) A multicentre, prospective, randomized,controlled study to evaluate the use of a fibrin sealant as an adjunct to sutured dural repair. $\mathrm{Br}$ J Neurosurg 29(1): 11-17. 


\section{International Journal of Surgery \& Surgical Techniques}

10. Kassam A, Horowitz M, Carrau R, Snyderman C, Welch $W$, et al. (2003) Use of Tisseel fibrin sealant in neurosurgical procedures: incidence of cerebrospinal fluid leaks and cost-benefit analysis in a retrospective study. Neurosurgery 52(5): 1102-1105.

11. Cappabianca P, Esposito F, Magro F, Cavallo LM, Solari D, et al. (2010) Natura Abhorret a Vacuo-use of fibrin glue as a filler and sealant in neurosurgical "dead spaces". Technical note. Acta Neurochir Suppl (Wien) 152(5): 897-904.

12. Terasaka S, Sawamura Y, Abe H (1994) Sealing effect of fibrin glue spray on protection of cerebrospinal fluid leakage through the dura mata. No Shinkei Geka 22(11): 1015-1059.

13. Kinaci A, Algra A, Heuts S, O Donnell D, van der Zwan A, et al. (2018) Effectiveness of Dural Sealants in Prevention of Cerebrospinal Fluid Leakage After Craniotomy: A Systematic Review. World Neurosurg 118: 368-376.

14. Cavallo LM, Solari D, Somma T, Savic D, Cappabianca $P$ (2014) The awake endoscope-guided sealant technique with fibrin glue in the treatment of postoperative cerebrospinal fluid leak after extended transsphenoidal surgery: technical note. World Neurosurg 82(3-4): 479-485.

15. Sekhar LN, Natarajan SK, Manning T, Bhagawati D (2007)The use of fibrin glue to stop venous bleeding in the epidural space, vertebral venous plexus, and anterior cavernous sinus: technical note. Neurosurg 61 (3): 51.

16. Wei X, Zheng X, Chen Z, Yuan Y, Li SJ (2019) Treatment of Venous Hemorrhage between Vestibulocochlear Nerve and Hypertrophic Flocculus During Microvascular Decompression Procedure for Hemifacial Spasm. Craniofac Surg 30(5): 1572-1575.

17. Crocker M, Nesbitt A, Rich P, Bell B (2008) Symptomatic venous sinus thrombosis following bone wax application to emissary veins. $\mathrm{Br} \mathrm{J}$ Neurosurg 22(6): 798-800.

18. Kasuya H, Kuroi Y, Yokosako S, Koseki H, Tani S (2018) Intra and postoperative bleeding in microvascular decompression for trigeminal neuralgia. World Neurosurg 118: 123-128.
19. Sawamura Y, Asaoka K, Terasaka S, Tada M, Uchida T (1999) Evaluation of application techniques of fibrin sealant to prevent cerebrospinal fluid leakage: a new device for the application of aerosolized fibrin glue. Neurosurgery 44(2): 332-337.

20. Basma J, Latini F, Ryttlefors M, Abuelem T, Krisht AF (2015) Minimizing Collateral Brain Injury Using a Protective Layer of Fibrin Glue: Technical Note. World Neurosurg 84(6): 2030-2036.

21. Todeschi J, Pin Y, Lersy F, Séverac F, Ollivier I, et al. (2018) The usefulness of fibrin glue as a support in the dissection of malignant cystic brain tumors. Neurochirurgie 64(1): 57-62.

22. Carless PA, Henry DA, Anthony DM (2003) Fibrin sealant use for minimising peri-operative allogeneic blood transfusion. Cochrane Database Syst Rev (2): CD004171.

23. Galan D, Monuszko K, Sankey EW, Zakare-Fagbamila R, Yang Z (2019) Fibrin glue as an adjuvant dural sealant reduces the rate of perioperative complications in posterior fossa decompression with duraplasty: A single center experience in 165 adult Chiari I patients. J Clin Neurosci 68: 80-85.

24. Van Overbeeke JJ, Cruysberg JR, Menovsky T (1998) Intracranial repair of a divided trochlear nerve. Case report. J Neurosurg 88(2): 336-339.

25. Draeger RW, Bynum DK, Patterson JMM (2017) Simplified Cable Nerve Grafting with Nerve-Cutting Guides and Fibrin Glue. J Hand Microsurg 9(3): 167169.

26. Koulaxouzidis G, Reim G, Witzel C (2015) Fibrin glue repair leads to enhanced axonal elongation during early peripheral nerve regeneration in an in vivo mouse model. Neural Regen Res 10(7): 1166-1171.

27. Martins RS, Siqueira MG, Da Silva CF, Plese JP (2005) Overall assessment of regeneration in peripheral nerve lesion repair using fibrin glue, suture, or a combination of the 2 techniques in a rat model. Which is the ideal choice? Surg Neurol 64: 1-16.

28. Childe JR, Regal S, Schimoler P, Kharlamov A, Miller MC, et al. (2018) Fibrin Glue Increases the Tensile Strength of Conduit-Assisted Primary Digital Nerve Repair. Hand (NY) 13(1): 45-49. 


\section{International Journal of Surgery \& Surgical Techniques}

29. Tisseel: Package Insert and Label Information. Italian version, March 2013, in, 2013.
30. http:// druginserts.com/lib/other/meds/tissell-1. 